\title{
Evaluation of the Impact of Presence Lighting and Digital Speed Limit Trailers on Interstate Speeds in Indiana Work Zones
}

\author{
Rahul Suryakant Sakhare1, Jairaj C. Desai', Jijo K. Mathew', John D. McGregor², \\ Darcy M. Bullock ${ }^{1}$ \\ ${ }^{1}$ Purdue University, West Lafayette, USA \\ ${ }^{2}$ Indiana Department of Transportation, Indianapolis, USA \\ Email: rsakhare@purdue.edu, desaij@purdue.edu, kjijo@purdue.edu,jmcgregor@indot.in.gov, darcy@purdue.edu
}

How to cite this paper: Sakhare, R.S., Desai, J.C., Mathew, J.K., McGregor, J.D. and Bullock, D.M. (2021) Evaluation of the Impact of Presence Lighting and Digital Speed Limit Trailers on Interstate Speeds in Indiana Work Zones. Journal of Transportation Technologies, 11, 157-167. https://doi.org/10.4236/jtts.2021.112010

Received: January 20, 2021

Accepted: March 20, 2021

Published: March 23, 2021

Copyright $\odot 2021$ by author(s) and Scientific Research Publishing Inc. This work is licensed under the Creative Commons Attribution International License (CC BY 4.0).

http://creativecommons.org/licenses/by/4.0/ (c) (i) Open Access

\begin{abstract}
Work zone safety continues to be one of the important focus areas for transportation agencies. Previous studies have identified that vehicle speed and lighting conditions are significant risk factors impacting work zone safety. This study evaluated the impact of the use of presence lighting and digital speed limit trailers on nighttime motorist speeds using commercially available connected vehicle speed data. Geospatial analysis was conducted on over 500,000 connected vehicle records to linear reference nearly 18,000 records from 195 unique trajectories to study section during the study period of 2 days. Results showed that median speeds reduced by 4 to $13 \mathrm{mph}$ from 11PM to 7AM during the deployment of presence lighting and speed limit trailers compared to base conditions. A Kolmogorov-Smirnov (KS) statistical test comparing 105 vehicles traveling through the construction zone with presence lighting and speed limit trailers with a group of 90 vehicles during base condition indicated the speeds during the deployment of presence lighting and speed limit trailers were lower than the base condition. Also, increased compliance with the $55 \mathrm{mph}$ speed limit was observed when the presence lighting and digital speed limit trailers were deployed. However, there were two hours (3AM to $5 \mathrm{AM}$ ) where speeds increased by $0-4 \mathrm{mph}$, perhaps due to the low volume at that hour. The encouraging results support the further deployment of presence lighting and speed limit trailers in nighttime construction zones for reducing vehicle speeds. Those future deployments should be monitored with connected vehicle speeds to collect additional data to broaden the evaluation of these speed mitigation techniques over a diverse set of construction zone activities.
\end{abstract}




\section{Keywords}

Work Zone Safety, Probe Data, Work Zone Practices, Speed Study, Construction Zone Speed Reduction

\section{Introduction}

In the United States, highway work zones have approximately 52,000 non-injury crashes, 24,000 injury crashes and 700 fatalities annually [1]. Reducing these incidents continues to be an important focus for transportation agencies and other stakeholders across the country. Previous studies have shown that crash rates on interstate sections with construction activity are significantly higher than those in non-work zone conditions [2] [3]. Vehicle speed is often a significant factor for crash incidents in work zones [4]. In addition, work zone lighting conditions also play an important role in impacting work zone safety [5] [6] [7]. Finley et al. [7] indicated a minimum lighting level of $5 \mathrm{fc}$ throughout the work area to ensure a safe environment for workers. Lighting levels as high as $20 \mathrm{fc}$ are recommended for precision work activities. However, the literature is quite sparse on the impact of work zone lighting on vehicle speeds.

Previously, transportation agencies have employed various mitigation techniques to curb work zone speeding including speed feedback trailers [8], law enforcement, and/or automated speed photo-radars [9] [10]. The combination of trailers and law enforcement has been shown to reduce the mean speeds of freeflowing cars by $8 \mathrm{mph}$ whereas law enforcement alone reduced the speeds by 6.1 to $6.4 \mathrm{mph}$ [9]. Studies have also shown that changeable message signs with radar significantly reduced vehicle speeds in the immediate vicinity of the signs [11]. Other studies have looked at the impact of fixed and variable speed limits on work zones. The variable speed limit signs outperformed the fixed signs in reducing the vehicle speeds [12] [13] [14]. Furthermore, the portable variable speed limits were also found to reduce speeds significantly in construction zones [15].

A mitigation strategy using presence lighting (PL) (Figure 1(a)) and digital speed limit trailers (DSL) (Figure 1(b)) is gaining popularity to improve compliance with work zone speed limits during night time operations. PL is a compact generator or battery-powered portable source of light that alerts nearby motorists of an upcoming lane closure or active construction activity but does not provide an alternative source of illumination for work zone activities. PL are generally placed ahead of the lane closures on interstates to provide the motorist the time to slow down before the actual start of the lane closure or work zone operations. Areas where traffic is entering or leaving work zones often present more complex driving situations because drivers may be changing lanes and merging. Each PL is capable of providing a minimum of 14,000 lumens illuminating a minimum area of approximately 3000 square feet (279 square meters) 
[16]. DSL are trailers mounted with dynamic speed limit signs. These 18-inch white LED displays are used to display the posted speed limit along roadways and work zones. Studies conducted by agencies using PL in active work zones have reported speed reductions in the range of 4 to $7 \mathrm{mph}$ [16] [17].

\section{Study Objective}

This study conducted an evaluation using commercially available connected vehicle speed data to evaluate the impact of PL and DSL trailers on nighttime motorist speeds and speed limit compliance on a rural section of Interstate 65 (I-65) in Indiana. The connected vehicle data source was chosen because it can provide detailed vehicle trajectories, with speed and position reported every 3 - 5 seconds for a random selection of vehicles approaching, traversing, and exiting the study work zone.

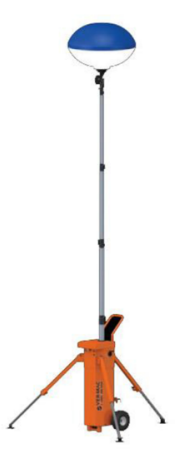

(a)

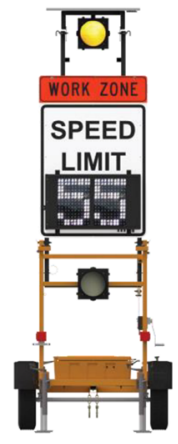

(b)
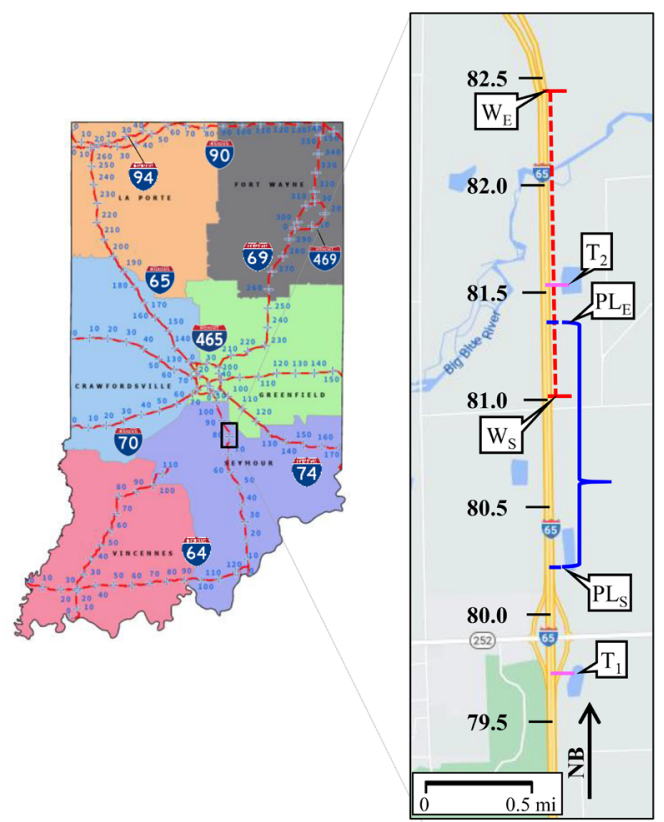

(c)

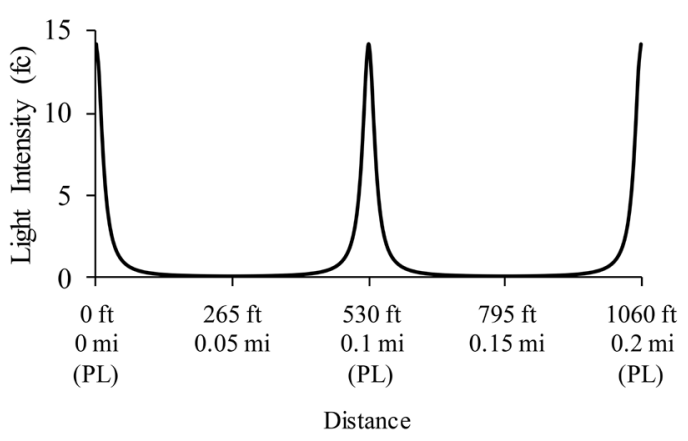

(d)

Figure 1. Study corridor and experimental setup. (a) Presence Lighting (PL); (b) Digital Speed Limit Trailer (T); (c) Indiana Interstate System Map with study location on I-65; (d) Light Intensity by distance due to PL at every 0.1 miles. 


\section{Study Corridor and Experimental Setup}

The study was conducted over a three-day period from Friday, September 11, 2020 to Sunday, September 13, 2020. Figure 1(c) shows the study location on I-65. Construction activity in the work zone was operational from 8:00PM on Friday to 3:00PM on Sunday. Callouts $\mathrm{W}_{\mathrm{S}}$ and $\mathrm{W}_{\mathrm{E}}$ denote the start and end of the active work zone with a right-lane closure spanning mile marker (MM) 81 to MM 82.5. Callouts $\mathrm{PL}_{S}$ and $\mathrm{PL}_{\mathrm{E}}$ show the start and end of the presence lighting units placed between MM 80.2 and MM 81.3. Presence lights, shown in Figure 1 (a), were set up in this stretch at an approximate gap of 0.1 miles (160 meters). The lighting intensity characteristics of the presence lights are shown in Figure 1 (d). The recommended lighting of $5 \mathrm{fc}$ or more in the work zone [7] is observed for $20 \mathrm{ft}$ (6 meters) distance around the PL. It does not provide an alternative for lighting conditions to perform work zone activities.

Two DSL trailers flashing the work zone speed limit of $55 \mathrm{mph}(88.5 \mathrm{kph})$, shown in Figure 1(b), were set up, one before the start of the work zone at MM 79.8 (callout $\mathrm{T}_{1}$ ) and a second within the work zone at MM 81.6 (callout $\mathrm{T}_{2}$ ).

\section{Evaluation Protocol}

PL and DSL were both active in the work zone (hereon referred to as "PL and DSL deployed") during the first night of operations, from 11:00PM on Friday to 7:00AM on Saturday. This was compared with regular work zone conditions when PL and DSL were inactive (hereon referred to as "base condition") on the following night from 11:00PM on Saturday to 7:00AM on Sunday. The evaluation was conducted by comparing motorist speeds between these nights using commercially available connected vehicle speed data. The hourly mean speeds at each time and location for all available trajectories within the section of interest were compared. Statistical tests were also performed to determine if the motorist speeds decreased significantly from the deployment of PL and DSL in the work zone.

\section{Probe Trajectory Data}

Commercially available connected vehicle trajectory data was analyzed for this study. The anonymized trajectory data provides a unique data point every 3 - 5 seconds with an associated timestamp, location, and speed for each vehicle trajectory. Geospatial filtering was conducted on more than 500,000 connected vehicle records during the study period to linear reference the records to the study section mile markers. The geospatial filtering generated nearly 18,000 records from 195 unique trajectories on this study section. Figure 2 shows the time-space diagram of these individual trajectories color coded by speed. The horizontal and vertical axis represents the time and interstate mile markers, respectively. Callouts $\mathrm{T}_{1}$ through $\mathrm{W}_{\mathrm{E}}$ across the vertical axis refer to the MM locations of DSL, PL and work zone as shown in Figure 1(c). Callout i (red box) refers to the work zone with PL and DSL deployed. Callout ii (blue box) refers to the regular work zone on the following night, base condition. Visual observations show the speeds drop- 
ping just before the start of the PL setup (callout iii), which indicates the possibility of drivers being alerted by the illuminated lights. It can also be observed from the plot that the construction activity in the work zone ended on Sunday afternoon around 3PM with speeds returning to normal soon after.

Figure 3(a) shows the zoomed-in view of the vehicle trajectories passing through the work zone with PL and DSL deployed (red box denoted by callout $\mathrm{i}$ on Figure 2). Figure 3(b) shows a similar time-space diagram of the work zone during base conditions (blue box denoted by callout ii on Figure 2). The analysis time period was restricted from 11PM to 7AM to exclude the effects of the observed congestion on Saturday night between 8PM and 11PM (callout iv) due to a crash on I-65. Additionally, sunrise on both mornings was around 7:20AM. It is possible that PL and DSL had a reduced impact during daylight conditions and hence the analysis was restricted to 7AM. Callout i on Figure 3 shows the speeds decreasing just before entering the PL zone. Visually comparing Figure 3 also shows that the speed reductions were more prominent in the work zone with PL and DSL deployed compared to the base condition.

\section{Data Analysis}

Hourly speed comparisons were performed for conditions with PL and DSL deployed and base condition. Figure 4(a) shows the comparison of cumulative frequency diagram (CFD) of speeds with PL and DSL deployed (callout i) and base condition (callout ii) for an hour between 11:00PM to 12:00AM. The CFD's were generated using more than 1200 speed records from nearly 25 unique trajectories captured during this hour. Dotted lines from bottom to top correspond to the $25^{\text {th }}$ percentile, median and $75^{\text {th }}$ percentile respectively. The posted work zone speed limit was $55 \mathrm{mph}$ as highlighted by the vertical dash-dotted line (callout iii) in Figure 4(a).

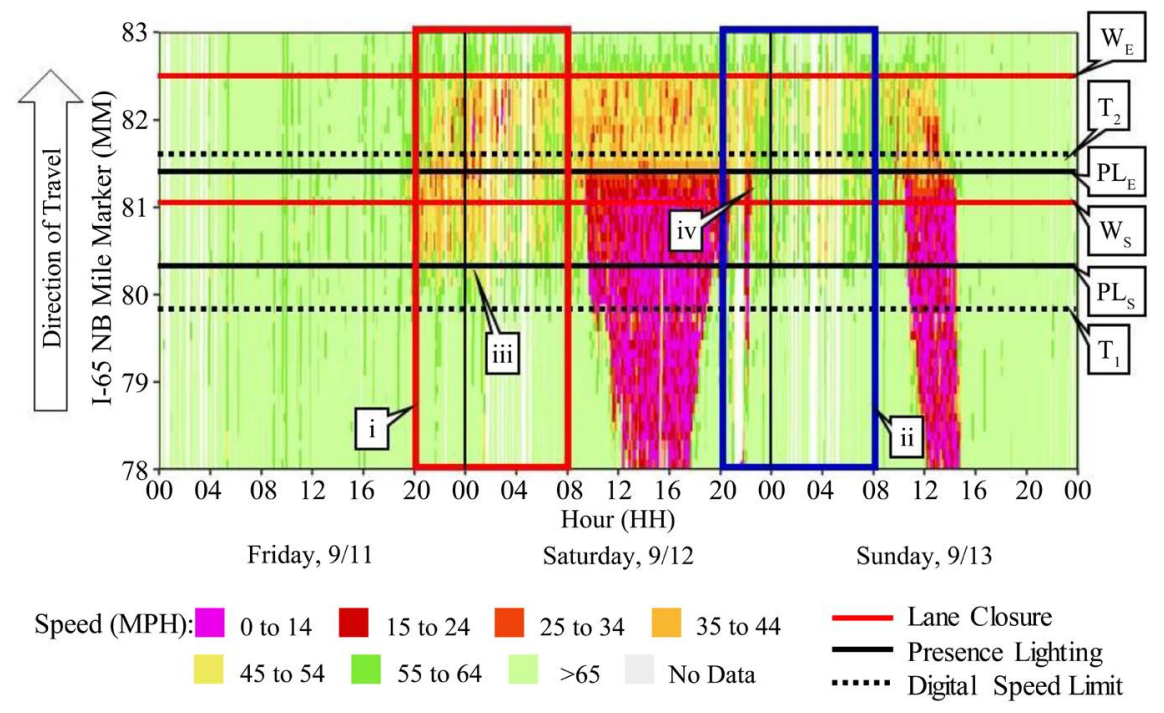

Figure 2. Time-space diagram of individual trajectories color-coded by speed along I-65 between MM 78 and MM 83 from Friday, 9/11 to Sunday 9/13. 


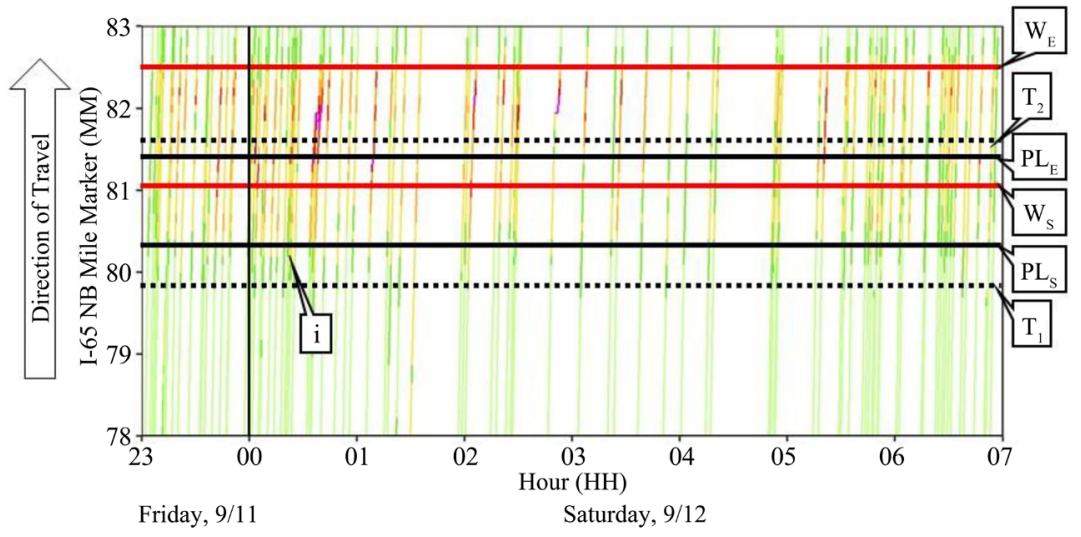

(a)

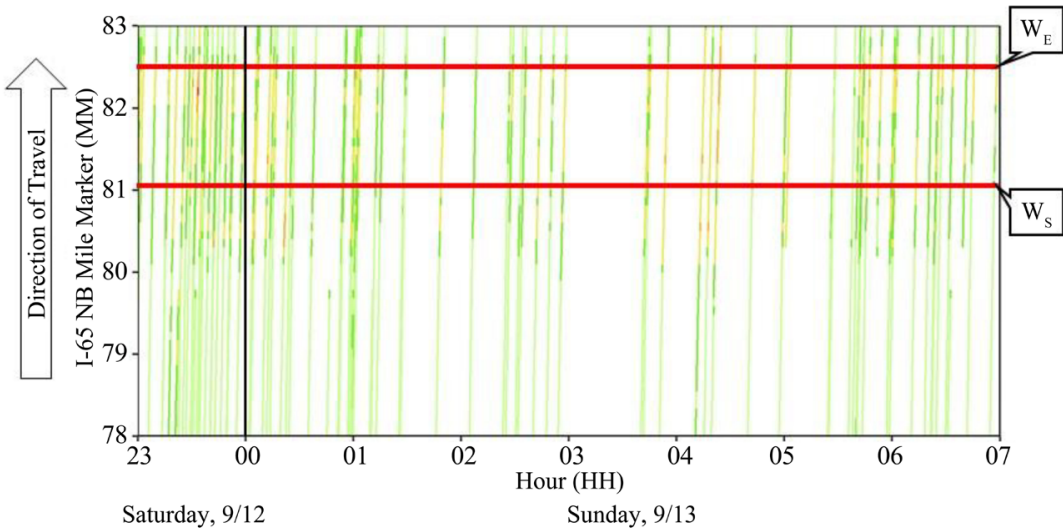

(b)

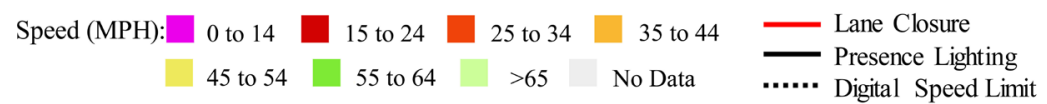

Figure 3. Time-space diagram of individual vehicle trajectories color-coded by speed along I-65 between MM 78 and MM 83. (a) 105 trajectories with 10,287 points from 11:00PM, Friday 9/11 to 7:00AM, Saturday 9/12 (with PL and DSL deployed); (b) 90 trajectories with 7649 points from 11:00PM, Saturday 9/12 to 7:00AM, Sunday 9/13 (during the base condition).

During this hour, median speeds throughout the work zone with PL and DSL deployed decreased by $7.2 \mathrm{mph}$ compared to speeds during the base condition. The maximum speed recorded with PL and DSL deployed was $79 \mathrm{mph}$ compared to $93 \mathrm{mph}$ during the base condition, a reduction of $14 \mathrm{mph}$. In addition, nearly $74 \%$ of speeds recorded with PL and DSL deployed were below the posted speed limit compared to only $34 \%$ in base condition.

Figure 4(b) illustrates a box and whisker plot showing the hourly variation in speeds. The blue plots correspond to the speeds during base condition and the red plots correspond to PL and DSL deployed. The bottom and the top of the error bar represent the minimum and maximum values of the recorded speed, respectively. The horizontal lines of the box represent the $75^{\text {th }}$ percentile, median and $25^{\text {th }}$ percentile from top to bottom. Additionally, Table 1 shows the hourly median speeds along with the corresponding number of trajectories and the samples. In general, the median speeds decreased with PL and DSL deployment 
for most of the hours, except between 3AM and 5AM. This could be due to the low sample size recorded during this period (less than 7 vehicles/hour) as seen in Table 1. Furthermore, lower volumes during these early hours could also have resulted in motorists speeding through the work zone.

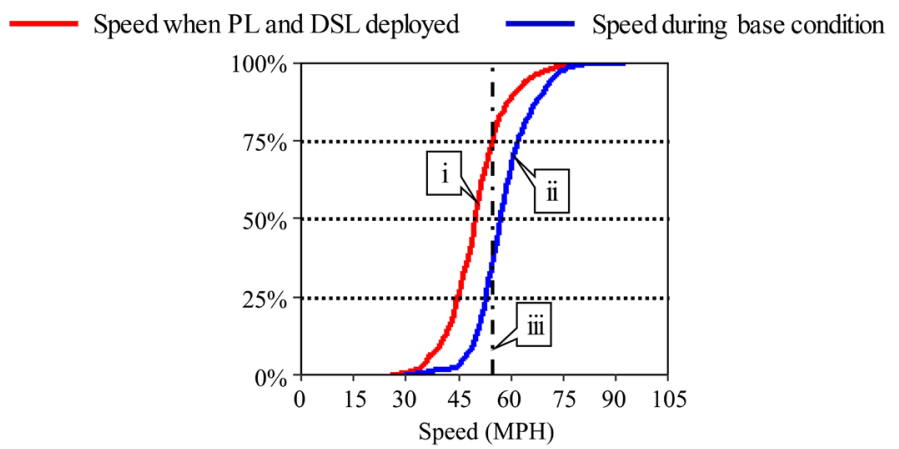

(a)

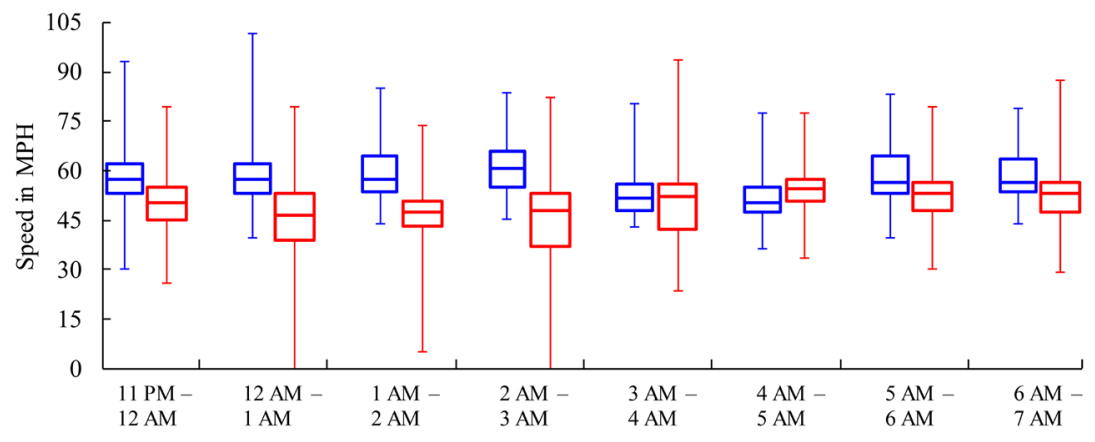

(b)

Figure 4. Comparison of hourly speeds in work zone during base condition (blue) and with PL and DSL deployed (red). (a) CFDs between 11:00PM and 12:00AM; (b) Hourly box-whisker plots from 11:00PM to 7:00AM during base condition setup (blue) for Saturday, 9/12-Sunday, 9/13 and with PL and DSL deployed (red) for Friday, 9/11-Saturday, $9 / 12$.

Table 1. Hourly Median Speeds and sample size in work zone with PL and DSL deployed and base condition.

\begin{tabular}{|c|c|c|c|c|c|c|c|}
\hline \multirow{2}{*}{ Hour } & \multicolumn{3}{|c|}{$\begin{array}{l}\text { Friday, } 9 / 11 \text {-Saturday, 9/12 } \\
\text { (PL and DSL deployed) }\end{array}$} & \multicolumn{3}{|c|}{$\begin{array}{l}\text { Saturday, } 9 / 12 \text {-Sunday, } 9 / 13 \\
\text { (base condition) }\end{array}$} & \multirow{2}{*}{$\begin{array}{c}\text { Median speed } \\
\text { difference (mph) } \\
{[a-b]}\end{array}$} \\
\hline & $\begin{array}{l}\text { Median speed } \\
\quad(\mathrm{mph})[\mathrm{a}]\end{array}$ & $\begin{array}{l}\text { Number of } \\
\text { trajectories }\end{array}$ & Sample size & $\begin{array}{l}\text { Median speed } \\
\quad(\mathrm{mph})[\mathrm{b}]\end{array}$ & $\begin{array}{l}\text { Number of } \\
\text { trajectories }\end{array}$ & Sample size & \\
\hline 11:00PM-12:00AM & 50.1 & 22 & 1266 & 57.3 & 25 & 1275 & -7.2 \\
\hline 12:00AM-1:00AM & 46.5 & 21 & 1500 & 57.3 & 14 & 689 & -10.8 \\
\hline 1:00AM-2:00AM & 47.2 & 8 & 398 & 57.3 & 10 & 449 & -10.1 \\
\hline 2:00AM-3:00AM & 48.0 & 10 & 669 & 60.8 & 8 & 413 & -12.8 \\
\hline 3:00AM-4:00AM & 52.3 & 5 & 314 & 51.9 & 3 & 178 & 0.4 \\
\hline 4:00AM-5:00AM & 54.4 & 7 & 407 & 50.1 & 5 & 278 & 4.3 \\
\hline 5:00AM-6:00AM & 53.0 & 14 & 824 & 56.5 & 13 & 533 & -3.5 \\
\hline 6:00AM-7:00AM & 53.0 & 18 & 1065 & 56.5 & 13 & 629 & -3.5 \\
\hline Average & 50.6 & 13.1 & 805.4 & 56.0 & 11.4 & 555.5 & -5.4 \\
\hline
\end{tabular}


Overall, the PL and DSL deployment saw a reduction in hourly median speeds between $3.5 \mathrm{mph}$ and $12.8 \mathrm{mph}$, as shown in Table 1 . The results concur with similar studies using PL that have shown reductions in spot speeds in the range of 4 to $7 \mathrm{mph}$ [16] [17]. The current study has shown a comparatively wider range of speed reduction due to the granularity of the connected vehicle data that was available throughout the section of the work zone.

Table 2 compares the percentages of hourly speed compliance with a posted speed limit of $55 \mathrm{mph}$ during the study period. The PL and DSL trailers were nearly 2 to 3.5 times as effective in complying with the posted speed limit as base conditions except during the early hours of lower volumes.

\section{Statistical Tests}

The Shapiro-Wilk normality test [18] [19] [20], a methodology to verify normality, was conducted to check if the speeds were normally distributed. The null hypothesis was rejected since the estimated p-value $(<0.01)$ was less than the level of significance (1\%), indicating that the speeds were not normally distributed.

The distribution of speeds with deployment of PL and DSL and during base condition were compared. The maximum absolute difference between the two cumulative distributions was observed around a speed of $50 \mathrm{mph}$. This value, called the D-statistic, can be used to evaluate the statistical goodness of fit between the two distributions with the Kolmogorov-Smirnov (KS) Test [21] [22]. The KS test was employed since the speeds were not normally distributed thus requiring a nonparametric test of equality. The one sided two-sample KS test was used to test whether the distribution of speed with deployment of PL and DSL is less than the distribution of speed during base condition. The null and alternate hypothesis for the KS test were constructed as shown in Equation (1).

$\mathrm{H}_{0}$ : The distribution of speeds with PL and DSL deployed $(A)$ is greater than or equal to the speeds during base condition $(B)\{A \geq B\}$,

$\mathrm{H}_{1}$ : The distribution of speeds with $\mathrm{PL}$ and DSL deployed $(A)$ is less than the speeds during base condition $(B)\{A<B\}$

Table 2. Percentage of hourly speed compliance with a posted speed limit of $55 \mathrm{mph}$.

\begin{tabular}{cccc}
\hline Hour & $\begin{array}{c}\text { Friday, 9/11-Saturday, 9/12 } \\
\text { (PL and DSL deployed }) \\
{[\mathrm{c}]}\end{array}$ & $\begin{array}{c}\text { Saturday, 9/12-Sunday, 9/13 } \\
\text { (base condition) } \\
{[\mathrm{d}]}\end{array}$ & $\begin{array}{c}\text { Ratio of } \\
\text { compliances } \\
{[\mathrm{c} / \mathrm{d}]}\end{array}$ \\
\hline 11:00PM-12:00AM & $74 \%$ & $34 \%$ & 2.2 \\
12:00AM-1:00AM & $85 \%$ & $39 \%$ & 2.2 \\
1:00AM-2:00AM & $90 \%$ & $34 \%$ & 2.7 \\
2:00AM-3:00AM & $82 \%$ & $23 \%$ & 3.6 \\
3:00AM-4:00AM & $63 \%$ & $67 \%$ & 0.9 \\
4:00AM-5:00AM & $57 \%$ & $75 \%$ & 0.8 \\
5:00AM-6:00AM & $67 \%$ & $35 \%$ & 1.9 \\
6:00AM-7:00AM & $64 \%$ & $35 \%$ & 1.8 \\
\hline
\end{tabular}


Table 3. Results from one sided two-sample KS test.

\begin{tabular}{cc}
\hline Parameter & Value \\
\hline $\mathrm{m}$ (sample size of A) & 6442 \\
$\mathrm{n}$ (sample size of B) & 4441 \\
$\mathrm{D}_{\mathrm{m}, \mathrm{n}}(\mathrm{D}$-statistic) & 0.3741 \\
$\mathrm{D}_{\mathrm{m}, \mathrm{n}, \alpha}($ critical value at significance level $\alpha=0.01)$ & 0.0296 \\
$\mathrm{p}$-value & $<2.2 \mathrm{e}-16$ \\
\hline
\end{tabular}

The results from the one sided two-sample KS test are shown in Table 3. The null hypothesis in Equation (1) was rejected since the D-statistic value (0.37) was greater than the critical value (0.029) at a significance level of $1 \%$. Results indicate that speeds with deployment of PL and DSL were significantly lower than those during the base condition.

\section{Conclusions}

Reducing the number of work zone crashes continues to be an important focus for transportation agencies and other stakeholders. Vehicle speed and lighting conditions have been reported as significant risk factors impacting work zone safety. This study evaluated the impact of PL and DSL trailers on nighttime motorist speeds on a section of I-65 in Indiana using commercially available connected vehicle speed data. Results showed that the median speeds reduced by 4 to $13 \mathrm{mph}$ from 11PM to 7AM during the deployment of PL and DSL compared to base condition (Table 1), which are consistent with results from previous studies using PL that showed similar speed reductions in the range of 4 to $7 \mathrm{mph}$ [16] [17]. A KS statistical test illustrated that the reduction in speeds were also statistically significant (Table 3). Also, increased compliance with the $55 \mathrm{mph}$ speed limit was observed when the PL and DSL trailers were deployed (Table 2). However, there were two hours (3AM to $5 \mathrm{AM})$ where speeds increased by $0-4$ $\mathrm{mph}$, perhaps due to low volume at that hour (Table 1).

The encouraging results support further development of presence lighting and speed limit trailers in nighttime constructions for reducing vehicle speeds. With increasing penetration levels, probe data will also have the potential to provide agencies with a timely alternative and cost-effective method to assess speed enforcement without the need to invest in expensive sensors.

\section{Acknowledgements}

The equipment for testing presence lighting and speed limit trailers was provided courtesy of Ver-Mac Inc. The trajectory data used in this study was provided by Wejo Ltd. The contents of this paper reflect the views of the authors, who are responsible for the facts and the accuracy of the data presented herein and do not necessarily reflect the official views or policies of the sponsoring organizations. These contents do not constitute a standard, specification or regulation. 


\section{Conflicts of Interest}

The authors declare no conflicts of interest regarding the publication of this paper.

\section{References}

[1] Khattak, A.J., Khattak, A.J. and Council, F.M. (2002) Effects of Work Zone Presence on Injury and Non-Injury Crashes. Accident Analysis \& Prevention, 34, 19-29. https://doi.org/10.1016/S0001-4575(00)00099-3

[2] Migletz, J., Graham, J.L., Anderson, I.B., Harwood, D.W. and Bauer, K.M. (1999) Work Zone Speed Limit Procedure. Transportation Research Record, 1657, 24-30. https://doi.org/10.3141/1657-04

[3] Ullman, G.L. and Krammes, R.A. (1991) Analysis of Accidents at Long-Term Construction Projects in Texas (Report No. FHWA/TX-90/1108-2).

[4] Garber, N.J. and Zhao, M. (2002) Distribution and Characteristics of Crashes at Different Work Zone Locations in Virginia. Transportation Research Record, 1794, 19-28. https://doi.org/10.3141/1794-03

[5] Li, Y. and Bai, Y. (2009) Highway Work Zone Risk Factors and Their Impact on Crash Severity. Journal of Transportation Engineering, 135, 694-701. https://doi.org/10.1061/(ASCE)TE.1943-5436.0000055

[6] Wong, J.M., Arico, M.C. and Ravani, B. (2011) Factors Influencing Injury Severity to Highway Workers in Work Zone Intrusion Accidents. Traffic Injury Prevention, 12, 31-38. https://doi.org/10.1080/15389588.2010.525569

[7] Finley, M.D., Ullman, G.L., Miles, J.D. and Pratt, M.P. (2013) Studies to Assess the Impact of Nighttime Work Zone Lighting on Motorists (Report No. FHWA/TX13/0-6641-1).

[8] Brewer, M.A., Pesti, G. and Schneider IV, W. (2006) Improving Compliance with Work Zone Speed Limits: Effectiveness of Selected Devices. Transportation Research Record, 1948, 67-76. https://doi.org/10.3141/1948-08

[9] Hajbabaie, A., Benekohal, R.F., Chitturi, M.V., Wang, M.-H. and Medina, J.C. (2009) Comparison of Effects of Automated Speed Enforcement and Police Presence on Speeding in Work Zones. Transportation Research Board 88 th Annual Meeting, Washington DC, 11-15 January 2009, 1-13. https://doi.org/10.3141/2096-12

[10] Benekohal, R.F., Hajbabaie, A., Medina, J.C., Wang, M. and Chitturi, M.V. (2010) Speed Photo-Radar Enforcement Evaluation in Illinois Work Zones (Research Report ICT-10-064).

[11] Wang, C., Dixon, K.K. and Jared, D. (2003) Evaluating Speed-Reduction Strategies for Highway Work Zones. Transportation Research Record, 1824, 44-53. https://doi.org/10.3141/1824-06

[12] Mekker, M.M., et al. (2016) Identifying Effects and Applications of Fixed and Variable Speed Limits (Report No. FHWA/IN/JTRP-2016/31). https://doi.org/10.5703/1288284316358

[13] McMurtry, T., Saito, M., Iffkin, M. and Heath, S. (2009) Variable Speed Limits Signs: Effects on Speed and Speed Variation in Work Zones. Transportation Research Board 88th Annual Meeting, Washington DC, 11-15 January 2009, 17.

[14] Lyles, R.W., Taylor, W.C., Lavansiri, D. and Grossklaus, J. (2004) A Field Test and Evaluation of Variable Speed Limits in Work Zones. Transportation Research Board 83rd Annual Meeting, Washington DC, 11-15 January 2004, 1-21. 
[15] Van Jura, J., Haines, D. and Gemperline, A. (2018) Use of Portable and Dynamic Variable Speed Limits in Construction Zones. Transportation Research Record, 2672, 35-45. https://doi.org/10.1177/0361198118794284

[16] Beaudry, S., Melin, T., Stone, R. and Tremblay, P. (2018) Portable Presence Light, Concepts \& Results.

[17] American Traffic Safety Services Association (2020) The Signal: An ATSSA Publication for the Roadway Safety Industry. 23.

[18] Shapiro, S.S. and Wilk, M.B. (1965) An Analysis of Variance Test for Normality (Complete Samples). Oxford Journals, 52, 591-611.

https://doi.org/10.1093/biomet/52.3-4.591

[19] Yap, B.W. and Sim, C.H. (2011) Comparisons of Various Types of Normality Tests. Journal of Statistical Computation and Simulation, 81, 2141-2155. https://doi.org/10.1080/00949655.2010.520163

[20] Razali, N.M. and Wah, Y.B. (2011) Power Comparisons of Shapiro-Wilk, Kolmogorov-Smirnov, Lilliefors and Anderson-Darling Tests. Journal of Statistical Modeling and Analytics, 2, 21-33. https://www.nrc.gov/docs/ML1714/ML17143A100.pdf

[21] Massey, F.J. (1951) The Kolmogorov-Smirnov Test for Goodness of Fit. Journal of the American Statistical Association, 46, 68-78. https://doi.org/10.1080/01621459.1951.10500769

[22] Gail, M.H. and Green, S.B. (1976) Critical Values for the One-Sided Two-Sample Kolmogorov-Smirnov Statistic. Journal of the American Statistical Association, 71, 757-760. https://doi.org/10.1080/01621459.1976.10481562 